\title{
Formulation, Optimization and In Vitro Evaluation of Solubility Enhanced Fast Disintegrating Tablets of Mebendazole
}

\author{
Desta Assefa*, Anteneh Belete and Nisha M. Joseph \\ College of Public Health and Medical Sciences, Jimma University, Ethiopia
}

\begin{abstract}
Mebendazole (MBZ) is used for the treatment of different intestinal helminthic infections (IHIs) and extraintestinal helminthic infections (EIHs). Due to its poor aqueous solubility and high first pass metabolism, MBZ has low bioavailability that can affect the therapeutic efficacy of the drug for ElHs. The aim of the present study is to develop solubility enhanced rapidly disintegrating tablets of $\mathrm{MBZ}$ with a simple and industrially feasible manufacturing process.

The influence of the selected excipients (nicotinamide (NIC), crospovidone and microcrystalline cellulose to mannitol ratio (MCC: MNTL)) on the physicochemical properties of MBZ were determined by using 32 factorial design. By using the shake flask method, NIC as hydrotropic agent enhanced solubility of MBZ more than 16 times in $40 \% \mathrm{w} / \mathrm{v}$ hydrotropic solution. Formulation (F8) which consisted of $5 \%$ crospovidone, $2: 1 \mathrm{MCC}$ : MNTL and $1 \mathrm{MBZ}$ : $3 \mathrm{NIC}$ hydrotropic solid dispersion (HSD) prepared by kneading method (KM1:3) had the shortest disintegration time (21 $\pm 1.7 \mathrm{sec})$, lowest wetting time $(56 \pm 3 \mathrm{sec})$ and largest crushing strength $\left(10.25 \pm 0.79 \mathrm{~kg} / \mathrm{cm}^{2}\right)$. These properties could be due to the binding and disintegrant properties of MCC and the disintegrant property of crospovidone. All of the formulations released more than $75 \%$ of the label claim within 20 min except formulation without NIC (F10). The rapid dissolution behavior is likely due to the formation of hydrotropic system.
\end{abstract}

Keywords: Mebendazole; Solubility enhancement; Nicotinamide; Hydrotropic solid dispersion; Fast disintegrating tablet; Optimization

\section{Introduction}

Helminthes as multicellular organisms can cause severe and even fatal human diseases [1,2]. They can be classified as intestinal helminthiasis which inhabit the human GIT and systemic helminthiasis which inhabit the liver, brain, lungs, kidneys, heart, thyroid and bone [3-5].

Anthelmintic like MBZ is a broad-spectrum drug which is effective for controlling and correct treatment of a number of nematodal and cestodal species of helminthes. It inhibits glucose uptake in the parasite resulting in glucose deficiency [4-7].

MBZ is recommended for the chemotherapy of non-surgical cases and as a supplementary treatment prior to and post-surgery of EIHs; such as alveolar and cystic hydatid disease. MBZ 40- $50 \mathrm{mg} / \mathrm{kg}$ per day for 3- 6 months have demonstrated efficacy $[2,8,9]$. The prolonged, highdose therapy used in the treatment of EIHs has been associated with alopecia, hepatocellular injury and bone marrow suppression $[6,10]$.

As MBZ is susceptible to high first pass elimination and poor water-soluble drug (BCS II), it can exhibit a number of negative clinical effects including potentially serious issues of inter-patient variability, erratic absorption (2-10\% of an oral dose absorbed) and limited efficiency against tissue-dwelling helminthes $[7,11]$. So, it requires innovative approaches to reach a sufficiently high bioavailability when administered by the oral route $[12,13]$.

Fast dissolving drug delivery system as a novel drug delivery system and a patient-oriented pharmaceutical preparation is designed to enhance the safety and efficacy of the drug molecule by formulating a dosage form which disintegrate or dissolve in a few seconds after placement in the mouth $[14,15]$. It can be administered easily to the geriatrics, pediatrics and patients suffering from dysphagia. It can bypass first pass elimination by undergoing pre-gastric absorption. This improves bioavailability of the drug and reduces dosing frequency and dose related untoward effects [16-18].

The fast disintegrating tablets (FDTs) can be prepared using various techniques; such as tablet molding, sublimation, lyophilization, direct compression and addition of disintegrants, etc. Cost effective technologies like direct compression and disintegrant addition can be easily adapted by pharmaceutical companies $[19,20]$.

Solubility is one of the most important parameters to achieve desired concentration of drug in systemic circulation to elicit pharmacological response $[21,22]$. Hydrotropy is one of the innovative approaches as solubilization method whereby addition of large amounts of a second solute results in an increase in the aqueous solubility of another sparingly soluble solute $[23,24]$. The use of hydrotropic agents has several advantages over other solubility enhancing methods; because it doesn't require chemical modification and system emulsification, eco-friendly, independent of $\mathrm{pH}$ and high selectivity [25,26]. Among hydrotropes, nicotinamide (NIC) has three special advantages which make it a very attractive agent. It has FDA approval status, very low toxicity and economical $[24,27,28]$.

$\mathrm{MBZ}$ is available in the forms of oral suspension $(500 \mathrm{mg} / 5 \mathrm{~mL})$, $100 \mathrm{mg}$ tablet, 100 and $500 \mathrm{mg}$ chewable tablet and administered orally $[10,29]$. In the present work, hydrotropy method was used to increase the solubility of MBZ using NIC as a suitable hydrotrope and FDT was prepared from MBZ HSD using crospovidone by direct compression.

*Corresponding author: Desta Assefa, College of Public Health and Medical Sciences, Jimma University, Ethiopia, Tel: +251913860017; E-mail: destaassefa24@yahoo.com

Received August 04, 2018; Accepted August 23, 2018; Published September 01, 2018

Citation: Assefa D, Belete A, Joseph NM (2018) Formulation, Optimization and In Vitro Evaluation of Solubility Enhanced Fast Disintegrating Tablets of Mebendazole. J Bioequiv Availab 10: 78-83. 382. doi: 10.4172/0975-0851.1000382

Copyright: $\odot 2018$ Assefa D, et al. This is an open-access article distributed under the terms of the Creative Commons Attribution License, which permits unrestricted use, distribution, and reproduction in any medium, provided the original author and source are credited. 
Citation: Assefa D, Belete A, Joseph NM (2018) Formulation, Optimization and In Vitro Evaluation of Solubility Enhanced Fast Disintegrating Tablets of Mebendazole. J Bioequiv Availab 10: 78-83. 382. doi: 10.4172/0975-0851.1000382

\section{Materials and Methods}

The materials used were MBZ (SupharmaChem, India), NIC (Lonza Guangzhou Ltd, China), crospovidone (China Associate Co. Ltd, Shenzhen, China), MCC (Avicel'MicrocelluloseWeissenborn $\mathrm{GmbH}+\mathrm{KG}$, Weissenborn, Germany) and MNTL (China Associate Co. Ltd, Shenzhen, China), Whatman filter paper, etc.

\section{Calibration curve of mebendazole}

As stock solution, $200 \mu \mathrm{g} / \mathrm{mL}$ were prepared using MBZ $(10 \mathrm{mg})$ and formic acid $(20 \mathrm{~mL})$. This solution was made up to $50 \mathrm{~mL}$ and diluted to $3-10 \mu \mathrm{g} / \mathrm{mL}$ solution using $0.1 \mathrm{~N} \mathrm{HCl}$. They were filtered by Whatman filter paper $(2.5 \mu \mathrm{m})$ and absorbance determined using UV-VIS spectrophotometer at $286 \mathrm{~nm}$ using formic acid and $0.1 \mathrm{~N}$ $\mathrm{HCl}$ mixture as blank. Finally, calibration curve was developed using absorbance and concentration data.

\section{Determination of equilibrium solubility of mebendazole in nicotinamide solutions}

Excess amount of MBZ was added to accurately measured $10 \mathrm{~mL}$ of $10,20,30$ and $40 \% \mathrm{w} / \mathrm{v}$ of hydrotropic solutions in $0.1 \mathrm{~N} \mathrm{HCl}$ and shaken ( $5 \mathrm{rpm}$ ) on orbital flask shaker for $48 \mathrm{~h}$; allowed to equilibrate for the next $48 \mathrm{~h}$ and centrifuged for $15 \mathrm{~min}$ at $2000 \mathrm{rpm}$ at room temperature.

The supernatant filtered and analyzed spectrophotometrically at $286 \mathrm{~nm}$ against corresponding blank reagent (hydrotropic solution in $0.1 \mathrm{~N} \mathrm{HCl}$ ). The experiment was performed in triplicate and the solubility of each preparation was estimated using calibration curve formula.

\section{Preparation of mebendazole hydrotropic solid dispersion}

By kneading technique, accurately weighed amount of MBZ and NIC were taken in a glass mortar and mixed for $5 \mathrm{~min}$. Then, $99.5 \%$ methanol was added drop by drop while triturating to get slurry like consistency for $15 \mathrm{~min}$. The uniform mass was dried in oven at $60^{\circ} \mathrm{C}$ for $4 \mathrm{~h}$. The dried HSD was pulverized and passed through sieve № 60 $(224 \mu \mathrm{m})$ and stored in screw capped glass vial until further evaluation.

In the solvent method, $99.5 \%$ methanol was used to dissolve the required amount of MBZ and NIC by continuous stirring with a magnetic stirrer for $30 \mathrm{~min}$ at room temperature. The paste formed was further dried in oven at $60^{\circ} \mathrm{C}$ for $4 \mathrm{~h}$. The resulting solid dispersions was scraped, pulverized and sieved through a № $60(224 \mu \mathrm{m})$ sieve and stored in screw capped glass vial at room temperature until further analysis.

Physical mixture (PM) was prepared by manually mixing MBZ and NIC of different ratios using glass mortar and pestle for $10 \mathrm{~min}$ duration. Finally, the mixture was passed through sieve № 60 .

\section{Compatibility study: Fourier transform infrared spectroscopy}

The compatibility between the drug and excipients used in the formulation was studied using Fourier transform infrared spectroscopy (FT- IR) (Shimadzu FTIR-8400S spectrometer, Japan). Samples of MBZ and HSD prepared by KM and PM of MBZ and crospovidone were grinded and mixed thoroughly with $\mathrm{KBr}$ at a $1: 5$ sample $/ \mathrm{KBr}$ ratio. The $\mathrm{KBr}$ discs were prepared by compressing the powders at a pressure of $5 \mathrm{~T}$ for $5 \mathrm{~min}$ in a hydraulic press. The scanning range was 400 to $4000 \mathrm{~cm}^{-1}$ and the resolution was $4 \mathrm{~cm}^{-1}$.

\section{In vitro dissolution tests of mebendazole hydrotropic solid dispersion}

In vitro dissolution rates of pure drug and different HSDs powder were studied using USP 36/NF 31 (Type II) dissolution test apparatus. A USP Apparatus II (paddle) was set-up with a rotational speed of 75 $\mathrm{rpm}$ and $500 \mathrm{~mL}$ of dissolution medium $(0.1 \mathrm{~N} \mathrm{HCl})$. The temperature was maintained at $37.0 \pm 0.5^{\circ} \mathrm{C}$ throughout the dissolution study. The amount of pure drug and HSD equivalent to $10 \mathrm{mg}$ of MBZ were spread on the surface of the medium $(0.1 \mathrm{~N} \mathrm{HCl})$. The $5 \mathrm{~mL}$ sample withdrawn at predetermined time points was filtered and analyzed by UV-VIS spectrophotometer at $286 \mathrm{~nm}$. The dissolution media replenished at each sampling time. All experiments were performed in triplicates and the cumulative amount of drug released from the system was estimated.

\section{Measurement of micromeritic properties}

Micromeritic properties like bulk density $(\rho b)$, tapped density $(\rho t)$, Hausner ratio (HR) and compressibility index (\% CI) of MBZ, HSD and formulations powder blend were studied.

Seventy grams of MBZ, HSD and each formulations powder blend were carefully introduced into a $250 \mathrm{~mL}$ graduated cylinder and the bulk volume of the powder was noted. After 500 times tapped using a tap densitometer, the tapped volume was noted.

\section{Preparation of solubility enhanced fast disintegrating tablets of mebendazole}

Nine FDT formulations were manufactured using HSD (KM1:3) by direct compression. The composition of tablet formulations (Table 1) were HSD (KM1:3), MCC, MNTL, crospovidone, magnesium stearate, talc and colloidal silicone dioxide $\left(\mathrm{cSiO}_{2}\right)$. All ingredients were passed through mesh aperture of $224 \mu \mathrm{m}$. HSD prepared by KM1:3, MCC, MNTL and crospovidone were blended for $10 \mathrm{~min}$. Magnesium stearate, talc and $\mathrm{CSiO}_{2}$ were added to the blend and the final blend was lubricated for $3 \mathrm{~min}$. Finally, the tablets were prepared by compression machine (punch 16/32) using suitable constant compression force.

\begin{tabular}{|c|c|c|c|c|c|c|c|}
\hline \multirow{2}{*}{ Formulations } & \multirow{2}{*}{ HSD (KM1:3) (\% w/w) } & \multirow[b]{2}{*}{ Crospovidone } & \multicolumn{5}{|c|}{ Excipients $(\% \mathrm{w} / \mathrm{w})$} \\
\hline & & & MCC & MNTL & Talc & Mg stearate & $\mathrm{CSiO}_{2}$ \\
\hline $\mathrm{F} 1$ & 66.67 & 0 & 14.79 & 14.79 & 1 & 0.75 & 2 \\
\hline $\mathrm{F} 2$ & 66.67 & 0 & 9.86 & 19.72 & 1 & 0.75 & 2 \\
\hline F3 & 66.67 & 0 & 19.72 & 9.86 & 1 & 0.75 & 2 \\
\hline $\mathrm{F} 4$ & 66.67 & 3 & 13.29 & 13.29 & 1 & 0.75 & 2 \\
\hline F5 & 66.67 & 3 & 17.72 & 8.86 & 1 & 0.75 & 2 \\
\hline F6 & 66.67 & 3 & 8.86 & 17.72 & 1 & 0.75 & 2 \\
\hline F7 & 66.67 & 5 & 12.29 & 12.29 & 1 & 0.75 & 2 \\
\hline F8 & 66.67 & 5 & 16.39 & 8.19 & 1 & 0.75 & 2 \\
\hline F9 & 66.67 & 5 & 8.19 & 16.39 & 1 & 0.75 & 2 \\
\hline
\end{tabular}

Table 1: Compositions of solubility enhanced fast disintegrating $600 \mathrm{mg} \mathrm{MBZ}$ tablet formulations. 
Citation: Assefa D, Belete A, Joseph NM (2018) Formulation, Optimization and In Vitro Evaluation of Solubility Enhanced Fast Disintegrating Tablets of Mebendazole. J Bioequiv Availab 10: 78-83. 382. doi: 10.4172/0975-0851.1000382

\section{Characterization of formulated tablets}

The tablets were evaluated according to the USP 36/NF 31; based on hardness, friability, disintegration time, wetting time and in vitro dissolution rate evaluation criteria. Six tablets were randomly taken from each formulation and tablet hardness was measured by using hardness tester.

Tablet friability was determined by taking previously weighed 10 tablets in friabilator and rotated at $25 \mathrm{rpm}$ for $4 \mathrm{~min}$. The tablets were taken out, dusted and reweighed. The percentage friability of the tablets was calculated.

Six tablets from each formulation were randomly selected and placed in a disintegration apparatus filled with $900 \mathrm{~mL}$ of distilled water kept at $37 \pm 2^{\circ} \mathrm{C}$. The time required for complete disintegration of the tablets with no palpable mass remaining in the apparatus was recorded as the disintegration time.

Three tablets of each formulation were taken and placed on Whatman filter paper, folded once diametrically and placed in 8 $\mathrm{mL}$ water and bromophenol blue containing Petri dish $(8.5 \mathrm{~cm}$ in diameter). The appearance of the dye on the surface of the tablet was taken as a sign for complete wetting and wetting time.

In vitro dissolution studies for the FDTs were carried out by using USP36 Type II dissolution apparatus at $75 \mathrm{rpm}$ in $900 \mathrm{~mL}$ of $0.1 \mathrm{~N}$ $\mathrm{HCl}+1 \%$ sodium lauryl sulphate as dissolution medium maintained at $37 \pm 0.5^{\circ} \mathrm{C}$. FDT of desired formulations was taken and placed in the vessels of dissolution apparatus. Sample of $10 \mathrm{~mL}$ were collected from the vessels at specified time intervals and replaced by blank medium. The sample filtered, and absorbance determined by UV-Visible spectroscopy at $286 \mathrm{~nm}$. Blank experiments were also performed at 286 $\mathrm{nm}$ for correction. Drug concentration was calculated and expressed as drug percentage released.

\section{Results and Discussion}

\section{Calibration curves of mebendazole}

MBZ calibration curve was prepared by using formic acid $+0.1 \mathrm{~N}$ $\mathrm{HCl}$ as solvent and the UV-VIS spectrophotometer method. The $0.1 \mathrm{~N} \mathrm{HCl}$ was used because it simulates gastrointestinal/ stomach environment.

UV-Visible spectral studies of MBZ at $286 \mathrm{~nm}$ showed the linearity range in the concentration range of $3-10 \mu \mathrm{g} / \mathrm{mL}$ (Figure 1).

\section{Equilibrium solubility of mebendazole in nicotinamide solutions}

The effect of NIC concentration on the solubility of MBZ was examined by the shake flask method. The solubility of MBZ in each preparation was determined using the formula:

$\uparrow$ Solubility = Solubility of MBZ in hydrotropic solution/ solubility of $\mathrm{MBZ}$ in $0.1 \mathrm{~N} \mathrm{HCl}$

Saturated solubility experiments showed that the concentration of MBZ in $0.1 \mathrm{~N} \mathrm{HCl}$ is notably affected by the presence of NIC (Figure 2). The solubility study diagram investigated in $0.1 \mathrm{NHCl}$ was positive curvature in a wide range of NIC concentrations. At $40 \% \mathrm{w} / \mathrm{v}$ concentration of NIC, the solubility of MBZ increased by more than 16 -fold. The results were in accordance with the formation of soluble complexes between hydrotropic agents and poorly water-soluble drugs. Different studies demonstrated intermolecular interactions between drug and NIC and wetting effect of NIC increase solubility and dissolution rate of poorly soluble drugs. The increase in solubility, however, was not a linear function of NIC concentration; suggesting the formation of higher order complexes $[28,30,31]$.

\section{Compatibility study: Fourier transform infrared spectroscopy}

The FT- IR spectrum of 1MBZ: 3NIC prepared by KM (Figure 3A) showed characteristic peaks of MBZ at 3363.62 for N-H stretching, 1458.08 for aromatic ring stretching and 2854 for $\mathrm{CH} 3$ stretching.

And, the PM of MBZ and crospovidone (Figure 3B) showed MBZ peaks near 3350 for $\mathrm{N}-\mathrm{H}$ stretching, near 2850 for $\mathrm{CH} 3$ stretching and at 1458.08 for aromatic ring stretching. Both KM prepared HSD and PM of MBZ and crospovidone showed the essential peaks for MBZ at 1458.08 for aromatic ring stretching. On the other hand, MBZ exhibits the broad infrared band around $2900 \mathrm{~cm}-1$ characteristic of benzimidazole in both PM and MBZ HSD prepared by KM (Figure 3C).

According to FT- IR study results, there was no major shift in the peak positions and retention of characteristic peaks for MBZ in MBZ HSDs and MBZ + crospovidone PM. Moreover, different studies showed that other ingredients used in this study, such as, aerosil,

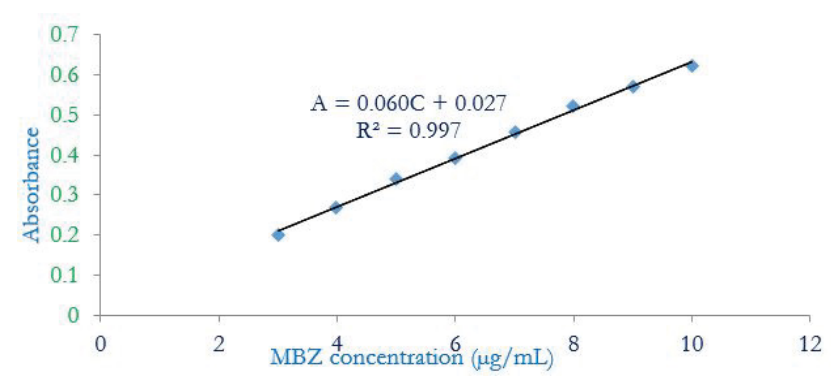

Figure 1: Calibration curve of mebendazole using formic acid $+0.1 \mathrm{~N} \mathrm{HCI}$ solution at $286 \mathrm{~nm}$.

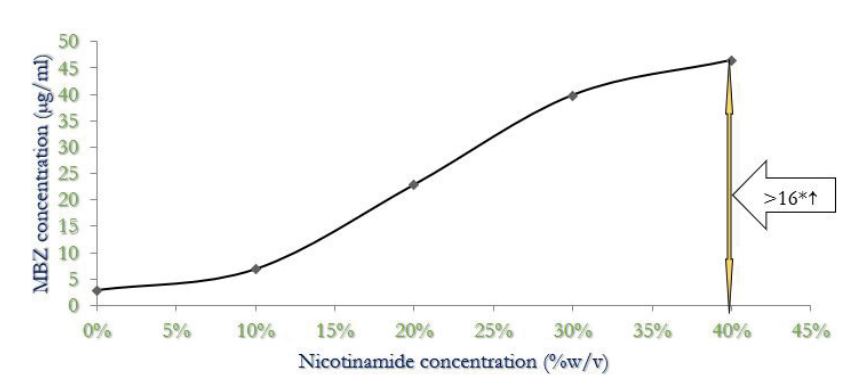

Figure 2: The influence of nicotinamide concentration $(\% \mathrm{w} / \mathrm{v})$ on the solubility of mebendazole in $0.1 \mathrm{~N} \mathrm{HCl}$ at room temperature.

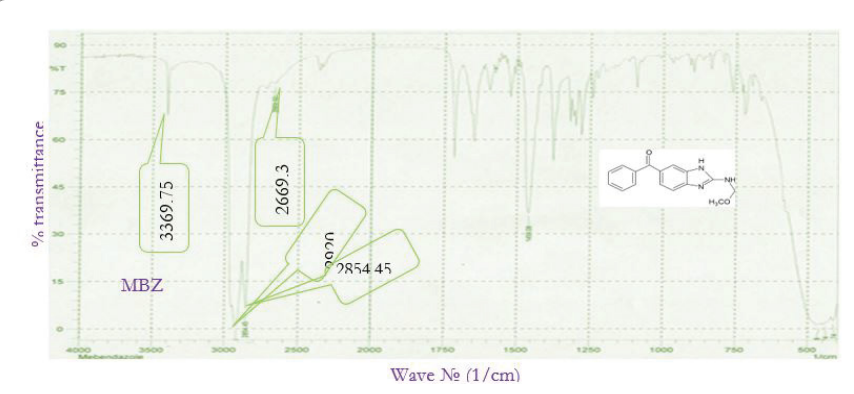

Figure 3A: Fourier transform infrared spectroscopy spectrum of mebendazole. 
magnesium stearate, MCC and MNTL, are used in the conventional MBZ tablet without affecting drug therapeutic effects.

\section{In vitro dissolution profiles of mebendazole hydrotropic solid dispersion}

In vitro dissolution study is the most significant evaluation parameter for any solid dosage form. MBZ alone and its' HSDs in vitro dissolution were carried out to determine the rate and extent of dissolution.

From the dissolution studies, depending on their drug release rate and amount within $90 \mathrm{~min}$, the HSD prepared by KM had greatest dissolution rate and amount than those prepared by physical method, solvent evaporation method and MBZ alone. KM is also the safest method compared to solvent evaporation and hot melt method (Figure 4) [32].

HSD prepared by KM with the lowest amount of hydrotropic carrier (KM1:1) showed low percentages dissolved within 90 min. A similar observation of concentration dependence of NIC on improving

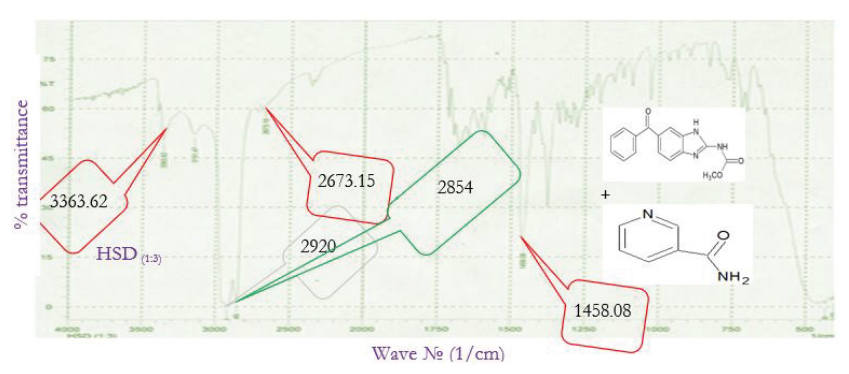

Figure 3B: Fourier transform infrared spectroscopy spectrum of 1 mebendazole: 3 nicotinamide hydrotropic solid dispersion.

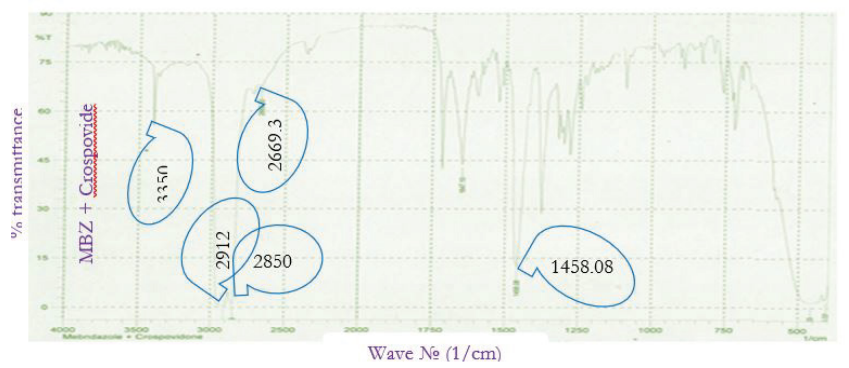

Figure 3C: Fourier transform infrared spectroscopy spectrum mebendazole + crospovidone physical mixture.

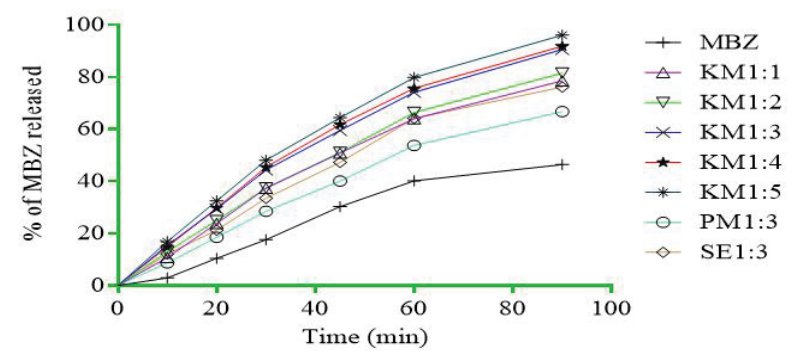

Figure 4: In vitro dissolution profiles of MBZ from pure MBZ and MBZHSD prepared by $\mathrm{KM}$, solvent evaporation (SE) and physical mixture in $0.1 \mathrm{~N} \mathrm{HCl}$ solution.

NB: The ratios indicate the MBZ: NIC amount in each preparation respectively. dissolution profile of poor water-soluble drugs was reported by Coffman, Kildsig and Evstigneev et al. $[23,33]$. Depending on the ratio of MBZ: NIC, there is no much difference in increment of dissolution rate and amount among KM 1:3, 1:4 and 1:5 ratio. So, HSD prepared by KM using 1MBZ: 3NIC (KM1:3) was used for developing FDT to enhance the solubility of poor water soluble MBZ.

\section{Micromeritic properties of mebendazole hydrotropic solid dispersions and different formulations' powder blend}

Powder flow properties are crucial in handling and processing operations such as flow from hoppers, mixing and compression. In recent years, the $\mathrm{CI}$ and the closely related HR have become simple, fast and popular methods of predicting powder flow characteristics.

Based on the results (Table 2), HSD preparation modified the \% CI and HR of MBZ; indicating the improvement of flow and compressibility. The \% CI values for all the formulation batches were found between $19.45 \pm 0.66 \%$ to $22.96 \pm 0.25 \%$; which is satisfactory for the powder flow and imply that the blends have good compressibility. HR values obtained were in the range of $1.24 \pm 0.01$ to $1.297 \pm 0.01$; which shows a passable flow property for the powder blend based on the USP [34]

Generally, the micromeritic properties indicated that HSDs possess improved flow and compacting properties compared to MBZ alone. Thus, MBZ HSDs would be more convenient for solid dosage form design and manufacture by direct compression.

\section{Characteristics of tablet formulations}

Preliminary experiments indicated that independent variables, such as MBZ: NIC ratio, percentage of crospovidone and MCC: MNTL were found to be the critical factors which affect the various responses. The main response variables investigated were tablet disintegration time, hardness and in vitro drug release within $90 \mathrm{~min}$. FDTs were prepared and examined visually that they were smooth. As tablet must show good mechanical strength in order to withstand handling during manufacturing, packaging and transportation, tablet hardness for all batches was found in the range between $6.6 \pm 0.35-10.25 \pm 0.79 \mathrm{~kg} /$ $\mathrm{cm}^{2}$. Friability values for all the formulations were found to be in the range of $0.39-0.66 \%$. The results obtained were found to be within the acceptable range $(<1 \%)$; indicating sufficient mechanical integrity and strength for the prepared tablets according to the USP [34].

For FDT, disintegration time is considered to be one of the important criteria in selecting the best formulation. As shown in Table 3 , the in vitro disintegration time ranged from $21 \pm 1.7-214 \pm 4.6 \mathrm{sec}$. Wetting time was determined for all the nine formulations (Table 3), and the results revealed that the wetting time ranged from $56 \pm 3.0-225$ $\pm 3.6 \mathrm{sec}$. Formulation (F8), which contains $5 \%$ crospovidone, 2:1 MCC: MNTL and MBZ: NIC (KM1:3) have the shortest disintegration time (21 $\pm 1.7 \mathrm{sec})$, lowest wetting time $(56 \pm 3.0 \mathrm{sec})$ and highest crushing strength $\left(10.25 \pm 0.79 \mathrm{~kg} / \mathrm{cm}^{2}\right)$. These properties could be due to the binding and disintegrant properties of MCC and the disintegration and hygroscopic properties of crospovidone.

The in vitro drug release behaviors of different formulations were studied. The USP36/NF31 (2013) specification for the release of MBZ from tablets states that not less than $75 \%$ of the label claims of MBZ should be dissolved in $120 \mathrm{~min}$ [34]. As can be seen in (Figure 5), all the formulations released more than $75 \%$ of the label claim within 20 min except formulation without NIC. Thus, all the FDT formulation, except F10 which doesn't contains NIC, passed the USP requirement for dissolution within $20 \mathrm{~min}$. 
Citation: Assefa D, Belete A, Joseph NM (2018) Formulation, Optimization and In Vitro Evaluation of Solubility Enhanced Fast Disintegrating Tablets of Mebendazole. J Bioequiv Availab 10: 78-83. 382. doi: 10.4172/0975-0851.1000382

\begin{tabular}{|c|c|c|c|c|}
\hline Formulation & pbulk $(g / m L) \pm s d$ & ptapped $(g / m L) \pm s d$ & $\mathrm{Cl}(\%) \pm \mathrm{sd}$ & $H R \pm s d$ \\
\hline MBZ alone & $0.22 \pm 1.12$ & $0.31 \pm 0.31$ & $29.0 \pm 2.10$ & $1.41 \pm 0.23$ \\
\hline HSD (KM 1:3) & $0.48 \pm 0.06$ & $0.59 \pm 0.11$ & $16.92 \pm 2.6$ & $1.20 \pm 0.06$ \\
\hline $\mathrm{F} 1$ & $0.46 \pm 0.00$ & $0.58 \pm 0.01$ & $20.69 \pm 0.70$ & $1.26 \pm 0.01$ \\
\hline $\mathrm{F} 2$ & $0.49 \pm 0.00$ & $0.60 \pm 0.02$ & $19.45 \pm 0.66$ & $1.24 \pm 0.01$ \\
\hline F3 & $0.45 \pm 0.01$ & $0.59 \pm 0.00$ & $22.70 \pm 0.00$ & $1.29 \pm 0.00$ \\
\hline $\mathrm{F} 4$ & $0.46 \pm 0.02$ & $0.58 \pm 0.01$ & $20.40 \pm 0.14$ & $1.26 \pm 0.00$ \\
\hline F5 & $0.46 \pm 0.03$ & $0.57 \pm 0.01$ & $20.30 \pm 0.27$ & $1.25 \pm 0.01$ \\
\hline F6 & $0.44 \pm 0.00$ & $0.58 \pm 0.03$ & $22.96 \pm 0.25$ & $1.29 \pm 0.00$ \\
\hline $\mathrm{F} 7$ & $0.43 \pm 0.00$ & $0.55 \pm 0.02$ & $21.98 \pm 0.07$ & $1.28 \pm 0.02$ \\
\hline F8 & $0.43 \pm 0.01$ & $0.56 \pm 0.13$ & $22.86 \pm 0.24$ & $1.29 \pm 0.01$ \\
\hline F9 & $0.46 \pm 0.00$ & $0.57 \pm 0.00$ & $20.0 \pm 0.15$ & $1.25 \pm 0.00$ \\
\hline
\end{tabular}

Table 2: Micromeritic properties of mebendazole alone, hydrotropic solid dispersion prepared by kneading method and powder blends.

\begin{tabular}{|c|c|c|c|c|c|c|}
\hline Formulation & Hardness $\left(\mathbf{k g} / \mathrm{cm}^{2}\right)$ & Friability (\%) & Disintegration time $(\mathrm{sec}) \pm \mathrm{sd}$ & Wetting time (sec) \pm sd & Weight variation $(\mathrm{mg})$ & Drug content (\%) \\
\hline F1 & $8.00 \pm 0.70$ & 0.52 & $134 \pm 2.5$ & $170.7 \pm 2.0$ & $581 \pm 1.44$ & $97.2 \pm 1.35$ \\
\hline $\mathrm{F} 2$ & $6.60 \pm 0.35$ & 0.64 & $214 \pm 4.6$ & $225 \pm 3.6$ & $590 \pm 0.72$ & $96.7 \pm 0.51$ \\
\hline F3 & $9.70 \pm 0.14$ & 0.39 & $56 \pm 4.6$ & $125 \pm 3.2$ & $582 \pm 1.25$ & $98.0 \pm 0.75$ \\
\hline F4 & $8.30 \pm 0.80$ & 0.52 & $29 \pm 2.3$ & $80 \pm 2.5$ & $596 \pm 1.20$ & $96.5 \pm 0.72$ \\
\hline F5 & $9.80 \pm 1.00$ & 0.40 & $25 \pm 0.58$ & $65 \pm 2.0$ & $590 \pm 1.23$ & $98.5 \pm 0.86$ \\
\hline F6 & $6.67 \pm 0.75$ & 0.65 & $34 \pm 0.58$ & $85 \pm 2.9$ & $579 \pm 1.02$ & $96.7 \pm 1.23$ \\
\hline $\mathrm{F} 7$ & $8.60 \pm 0.10$ & 0.53 & $26 \pm 0.58$ & $75 \pm 2.6$ & $580 \pm 0.87$ & $98.2 \pm 0.92$ \\
\hline F8 & $10.25 \pm 0.79$ & 0.41 & $21 \pm 1.7$ & $56 \pm 3.0$ & $572 \pm 1.33$ & $98.2 \pm 1.53$ \\
\hline F9 & $6.70 \pm 0.33$ & 0.66 & $31 \pm 3.2$ & $70 \pm 4.2$ & $585 \pm 1.43$ & $96.3 \pm 1.25$ \\
\hline
\end{tabular}

Table 3: Hardness, friability, disintegration and wetting times of solubility enhanced fast disintegrating tablets of mebendazole prepared for optimization.

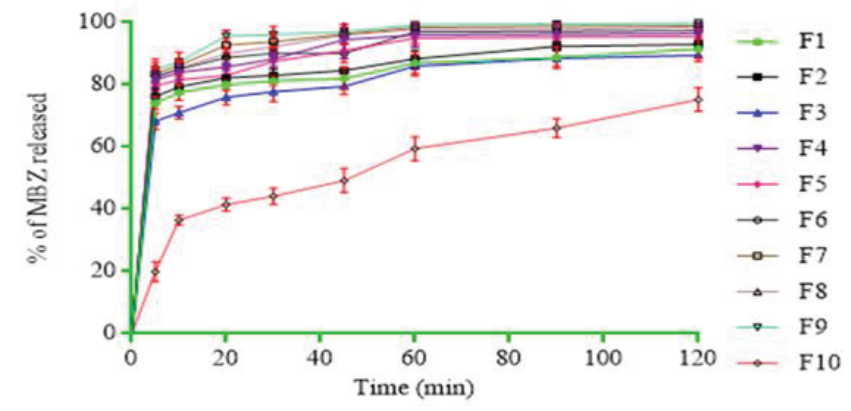

Figure 5: In vitro dissolution profiles of different optimized formulations of solubility enhanced mebendazole fast disintegrating tablets.

\section{Conclusion}

NIC enhanced the solubility of MBZ more than 16 times in $40 \%$ w/v hydrotropic solution. HSD powder of MBZ prepared using KM (1:3) showed the optimum in vitro drug release profile of MBZ. The rapid in vitro release behavior could be due to the fast dissolution time of NIC, together with its superior dispersibility and excellent wetting properties. The independent variables (crospovidone and MCC: MNTL) significantly affected the various responses; such as tablet hardness, disintegration time, friability and in vitro drug release of solubility enhanced FDTs. So, solubility enhanced FDTs of MBZ, which is suitable for paediatric, geriatric and other special population patients can be successfully developed by simple and feasible manufacturing method.

\section{Recommendations for Further Research}

- Investigate the in vivo drug release profile and performance of the optimized formulation;

- Determine the long-term stability study of the optimized batch in order to determine the shelf life of the product;
Perform optimized pilot scale and commercial scale production of the optimized formulation.

\section{Reference}

1. Eckert J, Deplazes P (2004) Biological, epidemiological, and clinical aspects of echinococcosis, a zoonosis of increasing concern. Clin Microbiol Rev 17: 107-135.

2. Coyle CM (2011) Echinococcosis: cystic and alveolar disease: Netter's infectious disease. 491-501.

3. Rivera JC, Hernandez-Campos A, Moreno-Esparza R, Navarrete-Vazquez G, Fuentes-Noriega I, et al. (2007) Biopharmaceutic evaluation of novel anthelmintic (1H-benzimidazol-5(6)-yl) carboxamidederivatives. Int J Pharm 343: $159-165$.

4. Dogru D, Kiper N, Ozcelik U, Yalcin E, Gocmen A (2005) Medical treatment of pulmonary hydatid disease: for which child? Parasitollnt 54: 135-138.

5. Hemphill A, Muller J (2009) Alveolar and cystic echinococcosis: towards novel chemotherapeutical treatment options. J Helminthol 83: 99-11.

6. Pearson RD, Weller PF, Guerrant RL (2011) Tropical infectious diseases: Principles, Pathogens and Practice. $3^{\text {rd }}$ Edn, pp: 76-94.

7. Bloom AK, Ryan ET (2013) Hunter's tropical medicine and emerging infectious disease. $9^{\text {th }}$ Edn, pp: 1085-1087.

8. Wen H, New RRC, Craig PS (1993) Diagnosis and treatment of human hydatidosis. Br J Clin Pharmac 35: 565-574.

9. Kern $P$ (2006) Medical treatment of echinococcosis under the guidance of Good Clinical Practice (GCP/ICH). Parasitollnt 55: 273-282.

10. Vadlamudi H, Reddy D, Raju P (2015) A critical analysis on the bioavailability enhancement approaches for mebendazole. JGTPS 6: 2528-2533.

11. Brusau EV, Cami GE, Narda GE, Cuffini S, Ayala AP, et al. (2008) Synthesis and characterization of a new mebendazole salt: mebendazole hydrochloride. J Pharm Sci 97: 542-552.

12. Chen JM, Wang Z, Wu CB, Li S, Lu TB (2012) Crystal engineering approach to improve the solubility of mebendazole. Cryst Eng Comm 14: 6221-6229.

13. Kaufman TS, Calvo NL, Maggio RM (2016) Mebendazole crystal forms in tablet formulations; An ATR-FTIR/chemometrics approach to polymorph assignment J Pharm Biomed Anal 122: 157-165. 
Citation: Assefa D, Belete A, Joseph NM (2018) Formulation, Optimization and In Vitro Evaluation of Solubility Enhanced Fast Disintegrating Tablets of Mebendazole. J Bioequiv Availab 10: 78-83. 382. doi: 10.4172/0975-0851.1000382

14. Watanabe $Y$, Ishikawa T, Utoguchi N, Matsumoto M (1999) Preparation and evaluation of tablets rapidly disintegrating in saliva containing bitter-tastemasked granules by the compression method. Chem Pharm Bull 47: 14511454.

15. Ibrahim HK, El-Setouhy DA (2010) Valsartan orodispersible tablets: formulation, in vitrolin vivo characterization. AAPS Pharm Sci Tech 11: 189-196.

16. Rahman Z, Zidan AS, Khan MA (2010) Risperidone solid dispersion for orally disintegrating tablet: its formulation design and non-destructive methods of evaluation. Int J Pharm 400: 49-58.

17. Liu CS, Zhang HB, Lei W, Zhang CW, Jiang B, et al. (2014) An alternative mebendazole formulation for cystic echinococcosis: The treatment efficacy, pharmacokinetics and safety in mice. Parasites and Vectors 7: 589.

18. Aljimaee Y, El-Helw A, Ahmed O, El-Say K (2015) Development and optimization of carvedilolorodispersible tablets: Enhancement of pharmacokinetic parameters in rabbits. Drug Des Devel The 9: 1379-1392.

19. Jeong SH, Takaishi Y, Fu Y, Park K (2008) Material properties for making fast dissolving tablets by a compression method. J Mater Chem 18: 3527-3535.

20. Madgulkar AR, Bhalekar MR, Padalkar RR (2009) Formulation design and optimization of novel taste masked mouth-dissolving tablets of tramadol having adequate mechanical strength. AAPS Pharm Sci Tech 10: 574-581.

21. ElmeshadAN, ElHagrasy AS (2011). Characterization and optimization of orodispersiblemosapride film formulations. AAPS Pharm Sci Tech 12: 13841392.

22. Khadka P, Ro J, Kim H, Kim I, Kim JT, et al. (2014) Pharmaceutical particle technologies: An approach to improve drug solubility, dissolution and bioavailability. AJPS 9: 304-316.

23. Coffman RE, Kildsig DO (1996) Effect of nicotinamide and urea on the solubility of riboflavin in various solvents. J Pharm Sci 85: 951-954.

24. Lee J, Lee SC, Acharya G, Chang C, Park K (2003) Hydrotropic solubilization of paclitaxel: Analysis of chemical structures for hydrotropic property. Pharm Res 20: 1022-1030.

25. Huh KM, Lee SC, Cho YW, Lee J, Jeong JH, et al. (2005) Hydrotropic polymer micelle system for delivery of paclitaxel. J Control Release 101: 59-68.

26. Kim JY, Kim S, Papp M, Park K, Pinal R (2010) Hydrotropic solubilisation of poorly water soluble drugs. J Pharm Sci 99: 3953-3965.

27. Hussain AA, Rasool AA, Dittert LW (1991) Solubility enhancement of some water-insoluble drugs in the presence of nicotinamide and related compounds. J Pharm Sci 80: 387-393.

28. Aggarwal AK, Jain S (2011) Physicochemical characterization and dissolution study of solid dispersions of ketoconazole with nicotinamide. Chem Pharm Bull 59: 629-638.

29. García-Rodriguez JJ, Torre-Iglesias PM, Vegas-Sánchez PC, Torrado-Durán S, Bolás-Fernández F, et al. (2011) Changed crystallinity of mebendazole solid dispersion: improved anthelmintic activity. Int J Pharm 403: 23-28.

30. HussainMA, Diluccio RC, Maurin MB (1993) Complexation of moricizine with nicotinamide and evaluation of the complexation constants by various methods. J Pharm Sci 82: 1992-1994.

31. Biswals, Sahoo J, Murthy PN, Giradkar RP, Avari JG (2008) Enhancement of dissolution rate of gliclazide using solid dispersions with polyethylene glycol 6000. AAPS Pharm Sci Tech 9: 563-570.

32. Bikiaris DN (2011) Solid dispersions, part I: recent evolutions and future opportunities in manufacturing methods for dissolution rate enhancement of poorly water-soluble drugs. Expert Opin Drug Deliv 8: 1501-1519.

33. Evstigneev MP, Evstigneev VP, Santiago HA, Davies DB (2006) Effect of a mixture of caffeine and nicotinamide on the solubility of vitamin (B2) in aqueous solution. Eur J Pharm Sci 28: 59-66.

34. 2013 United States Pharmacopeia and National Formulary (USP 36-NF 31) Rockville, MD: United States Pharmacopeia Convention. 